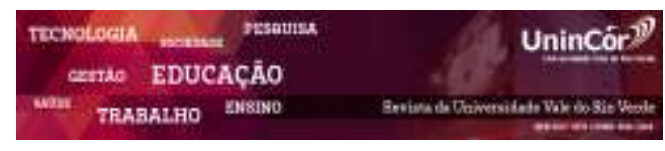

Revista da Universidade Vale do Rio Verde ISSN: 1517-0276 / EISSN: 2236-5362 Vol. 16 | n. 2 | Ano 2018

João Batista Ferreira Faculdade Cidade de Coromandel coordenacaoadmfcc@hotmail.com

Maicon Figueiredo Ferreira Faculdade Cidade de Coromandel admfcc2016@gmail.com

\section{A UTILIZAÇÃO DO MARKETING DIGITAL EM UMA EMPRESA PRESTADORA DE SERVIÇOS}

\section{RESUMO}

A tecnologia é um recurso que afetou profundamente a forma de fazer negócios, exigindo um novo comportamento das organizações, seja para anunciar seus produtos e serviços, seja para interagir com seus clientes. A partir dessa contextualização, o objetivo geral desta pesquisa foi o de analisar a eficiência dos recursos de marketing digital utilizados pela empresa prestadora de serviços automotivos. Por conseguinte, os objetivos específicos, foram compostos por conhecer o perfil do cliente da empresa; verificar a satisfação dos clientes com relação ao atendimento que a empresa realiza por meio dos canais digitais; apontar se as ferramentas de marketing digital são reconhecidas pelos clientes; identificar se as ferramentas de marketing digital utilizadas pela empresa representam um diferencial competitivo. Tratou-se de uma pesquisa descritiva, quantitativa e estudo de caso, cuja coleta de dados aconteceu por intermédio da aplicação de questionário a 50 clientes da empresa em questão. Os dados foram analisados sob a ótica quantitativa e apresentados sob a forma de tabelas. Evidenciou-se que a grande maioria dos participantes apontou que não conhecem a página da empresa no Facebook, não usam SMS, nem e-mail ou Whatsapp para contatar a organização. Esse fato abre brechas para que a empresa explore tais ferramentas, tornandoas mais atrativas e fixando para seus clientes as mesmas como canais de comunicação para com a empresa, uma vez que tais ferramentas possuem custo zero ou baixo custo se comparadas a outras mídias.

Palavras-chave: Canais digitais. Marketing. Marketing digital.

\section{THE USE OF DIGITAL MARKETING IN A SERVICE PROVIDER}

\begin{abstract}
Technology is a feature that has profoundly affected the way we do business, requiring new organizational behavior, whether to advertise its products and services or to interact with its customers. From this context, the overall objective of this research was to analyze the efficiency of the digital marketing resources used by the company providing automotive services. Therefore, the specific objectives were composed of knowing the profile of the client of the company; verify the satisfaction of customers with regard to the service that the company carries out through digital channels; to point out if digital marketing tools are recognized by customers; to identify if the digital marketing tools used by the company represent a competitive differential. This was a descriptive, quantitative and case study, whose data collection was done through the application of a questionnaire to 50 clients of the company in question. The data were analyzed from a quantitative perspective and presented in the form of tables. It was evidenced that the vast majority of
\end{abstract}


participants pointed out that they do not know the company's Facebook page, do not use SMS, nor email or Whatsapp to contact the organization. This fact opens up loopholes for the company to explore such tools, making them more attractive and setting their customers the same as communication channels to the company, since such tools have zero cost or low cost compared to other media.

Keywords: Digital channels. Marketing. Digital marketing.

Recebido em: 03/03/2018 - Aprovado em: 31/03/2018 - Disponibilizado em: 15/12/2018

\section{INTRODUÇÃO}

Todas as organizações utilizam-se dos conhecimentos de marketing para atingir seus clientes e, assim, satisfazê-los. Ainda que os conceitos usados não envolvam tecnologia, ou sejam tradicionais, contribuem para o alcance dos objetivos organizacionais. Todo o desenvolvimento desse segmento da Administração, nos últimos anos, contribuiu para a concepção de que as atividades do marketing e da organização devem estar voltadas para a satisfação das necessidades do consumidor. Dentro dessa realidade, o marketing acabou por se adaptar às novas tecnologias, transformandose em marketing digital, para atender tanto as demandas dos consumidores, quanto da própria empresa.

De acordo com Solomon (2011), atualmente as empresas estão se voltando para o marketing digital como uma das alternativas que geram mais oportunidade de negócios, proporcionando agilidade aos processos e à comunicação com o cliente, bem como à produção de conteúdo e o relacionamento com os consumidores.
Mas o marketing digital ainda é assunto novo e está em constante desenvolvimento. Essas questões merecem estudos para maior compreensão, especialmente quando aplicado em um estudo de caso, como foi na pesquisa em questão. Assim, a realização desta pesquisa se justifica, em função de os consumidores terem assumido o comando dos recursos tecnológicos, das mídias sociais, dos blogs, redes sociais e sites colaborativos, transformando e influenciando a relação dos consumidores com as empresas, marcas e produtos.

A tecnologia é um recurso que afetou profundamente a forma de fazer negócio, exigindo um novo comportamento das organizações, seja para anunciar seus produtos e serviços, seja para interagir com seus clientes. $\mathrm{O}$ marketing também teve que se adequar a essa nova transformação social.

$$
\text { Por essa razão, é importante }
$$
compreender de que maneira o marketing, em sua forma digital, é utilizado pelas organizações. Por isso, esta pesquisa teve como problema norteador a seguinte questão: os recursos de marketing digital utilizados pela empresa de Limpeza Automotiva são eficientes, segundo a visão de seus clientes? 
Este trabalho se torna relevante pela necessidade de compreender como os recursos de marketing digital estão contribuindo, para os negócios de uma empresa prestadora de serviços automotivos. Assim, o estudo representa uma oportunidade de estabelecer uma correlação entre a literatura (vida acadêmica) e a prática profissional (análise na organização), contribuindo para a formação da pesquisadora. Para a organização, representou uma oportunidade de refletir sobre suas práticas, se estão adequadas ou se podem sofrer melhorias, sempre prezando pela satisfação de seus clientes.

A partir dessa contextualização, o objetivo geral desta pesquisa foi analisar a eficiência dos recursos de marketing digital utilizados pela empresa;

Por conseguinte, os objetivos específicos, foram compostos por conhecer o perfil do cliente da empresa; verificar a satisfação dos clientes com relação ao atendimento que a empresa realiza por meio dos canais digitais; apontar se as ferramentas de marketing digital são reconhecidas pelos clientes; identificar se as ferramentas de marketing digital utilizadas pela empresa representam um diferencial competitivo.

\section{REFERENCIAL TEÓRICO}

\subsection{Da tecnologia à internet: a base para o marketing digital}

A tecnologia está cada vez mais presente na vida das pessoas. Seja no trabalho, nos estudos ou nas relações sociais. Os últimos avanços interferiram na forma como os indivíduos se relacionam. Além de seu surgimento, os indivíduos e as organizações precisam conviver com as constantes atualizações. A tecnologia não se aplica a uma única área do conhecimento humano, mas a qualquer uma delas. As palavras tecnologia e técnica têm origem comum, na palavra grega techné, que significa "alterar o mundo de forma prática", ferramenta ou instrumento. Nesse sentido, tecnologia pode ser conceituada como a razão do saber fazer (VERAZTO et al., 2008).

De acordo com Silva (2002), ao longo da história a tecnologia não deve ser compreendida apenas como a descoberta e construção sucessiva de instrumentos. Deve ser percebida como um encadeamento de circunstâncias sociais que ora favoreciam, ora prejudicavam, o esforço humano de desenvolver novos instrumentos e modificar o mundo a seu redor, gerando, também, melhores condições de vida.

As inovações tecnológicas não estão restritas à informática, mas é inegável o quanto o desenvolvimento de hardwares (parte material) e softwares (aplicativos) vinculados à informática modificou as relações entre as pessoas, as organizações, o Estado e deles entre si.

Para Padoveze (2004, p. 51) a “tecnologia da informação (TI) é todo o conjunto tecnológico à disposição das empresas para efetivar seu subsistema de informação e suas operações”. Esse conjunto, normalmente, está ligado à informática e às telecomunicações, bem como a todo o desenvolvimento científico do processo de transmissão espacial de dados.

As organizações estão buscando, a cada dia, o uso mais intenso e amplo da TI, não apenas enquanto jargão, mas como uma 
ferramenta empresarial que altere as bases da competitividade e das estratégias empresariais.

Para Pasa (2001), a tecnologia da informação proporciona às organizações uma forma eficiente de comunicação e informação. É a base fundamental de toda a revolução que vem modificando o modo de se fazer negócios no mundo, abrindo oportunidades para que as empresas possam atuar de forma eficiente, oferecendo serviços melhores para seus clientes.

\subsection{Marketing}

O marketing concentra-se em conhecer o comportamento dos indivíduos e a partir disso, satisfazer seus anseios. Ao longo do tempo seu conceito evoluiu, deixando de ser visto como uma ferramenta para estimular a venda de produtos e serviços, que pessoas não desejavam, para voltar-se para o atendimento da satisfação e necessidades do consumidor.

Kotler e Keller (2006, p. 04) conceituam marketing de forma bastante simples e objetiva, em uma única frase: o "marketing envolve a identificação e a satisfação das necessidades humanas e sociais", suprindo as demandas geradas pelos consumidores. Esse é um modelo bastante adotado pelas organizações atualmente.

Segundo Cobra (2009), apesar de muito se falar sobre o poder do marketing em influenciar e convencer as pessoas a comprarem determinados produtos ou serviços, não existe evidência científica de que a demanda seja estimulada por forças externas. Portanto, por melhor que seja o marketing, dificilmente o consumidor comprará algo que não lhe agrade e não atenda a suas necessidades ou desejos específicos.
Existem diversos tipos de marketing, os quais se aplicam nas mais diversas áreas. Destacam-se o marketing digital, industrial, o de varejo, institucional, de produto ou serviços, financeiro e o marketing internacional (SILVA, 2005).

\subsubsection{O marketing digital}

As empresas cada vez mais tem utilizado o marketing digital em suas ações, visando ampliar seu potencial competitivo e seu lucro. Isso foi possível graças à disseminação da tecnologia e acesso à internet, que permitiu desenvolvimento de novas formas de comunicação entre as empresas, e entre estas e seus consumidores.

Para Costa et al. (2015), o marketing digital, também chamado de marketing online, é o marketing integrado à internet, tornando mais fácil o contato entre empresa e cliente, contribuindo para a troca de produtos entre fornecedores e consumidores. Cintra (2010), conta que a internet popularizou-se e tornou-se um importante meio de comunicação, acessível a todos, desde o ano 2000. Esse acesso permitiu que o marketing digital fosse ampliado, influenciando a forma como consumidores compram algo, obtém informações e veem a opinião de outros consumidores.

Gabriel (2010, p. 104) conceitua marketing digital como "o marketing que utiliza estratégias em algum componente digital no marketing mix - produto, preço, praça ou promoção". Reforça que modelos antigos de comunicação e promoção têm pouco ou nenhum espaço no marketing atual, que exige mais 
dinamismo e flexibilidade, já que o mercado tornou-se mais competitivo.

Esses novos padrões de comportamento influenciam o mercado e afetaram a forma como o marketing organizacional é realizado. Segundo Amâncio (2009), o marketing nesse novo ambiente está voltado para a tecnologia e os clientes, transformando o diálogo entre produtor e consumidor. $\mathrm{O}$ consumidor passou a estar disperso em todo o planeta e não apenas concentrado em locais onde era possível a empresa se deslocar fisicamente.

O marketing digital pode acontecer por meio de diversas ferramentas, sendo elas: newsletters, websites, banners, publicidade online, widgets, vídeos, e-mails, telefone celular, redes sociais, como Facebook e Instagram, dentre outros. Mas não é suficiente transpor o conteúdo tradicional para as mídias digitais; é preciso redirecionar a visão de mercado para o público, incluindo o novo público mais jovem e adepto às tecnologias (AMÂNCIO, 2009).

Para Mckenna (2005), antes de iniciar as atividades digitais, é preciso que a empresa identifique seu público, os produtos que esse público deseja, a melhor forma de se comunicar com esse grupo e, então, desenvolver as ações de marketing que atendam a esse contexto. $\mathrm{O}$ bom marketing continua valendo, mas adaptado ao mundo digital.

\subsubsection{Comunidades virtuais e redes sociais}

As organizações e comunidades se constituem a partir de um determinado agrupamento social. Neste sentido, pode-se dizer que a organização é composta pela interação social que constitui as relações de determinado grupo. No entanto, quando trabalha-se com o ciberespaço, a interação social dá-se de uma maneira muito particular. Trata-se de uma interação mediada pelo computador, ou seja, não há contato físico entre os indivíduos que dela participam (REQUETO, 2006).

Segundo Primo (2007), as comunidades virtuais são agregações sociais que emergem na internet, quando um número de pessoas conduz discussões públicas por um tempo determinado, com suficiente emoção, e que forma teias de relações pessoais no ciberespaço.

Para Warren (2006), as redes sociais são resultados do processo articulatório humano. Esta rede pressupõe a identificação de sujeitos coletivos em torno de valores, objetivos ou projetos em comum, os quais definem os atores ou situações sistêmicas antagônicas que devem ser combatidas e transformadas. A ideia de rede de movimento social éum conceito de referência que busca apreender o porvir ou o rumo das ações de movimento, transcendendo as experiências empíricas, concretas, datadas, localizadas dos sujeitos/atores coletivos.

No entendimento de Moraes (2000), o sucesso das redes sociais virtuais aconteceu por este ser um ambiente interativo, cooperativo e descentralizado da internet, o que introduziu um componente inesperado e criativo. Inúmeros atores, organizados ou não, ainda que eventualmente separados por estratégias e táticas de ação, descobriram no ciberespaço as possibilidades de difundir suas reivindicações. E ainda puderam superar os filtros ideológicos e as políticas editoriais da grande mídia. Sem a pretensão de atingir milhões de pessoas, buscou promover a disseminação de ideias e o máximo 
de intercâmbios, interagindo com quem quisesse apoiar, criticar, sugerir ou contestar.

Requeto (2006), também destaca que as interações que ocorrem no ambiente virtual, e mais precisamente nas redes sociais virtuais, decorrem de uma interação mútua, onde é possível interagir com várias pessoas simplesmente através de botões. Essas interações têm impacto social, já que têm também reflexos nos dois pólos da relação comunicativa. Por outro lado, essas relações também permitem a inventividade, o que pode gerar relações mais complexas do ponto de vista social. A cooperação obtida nas interações mútuas permite que esse conjunto de um grupo ou de indivíduos consiga um objetivo comum, sendo, deste modo, essencial para a existência das estruturas sociais.

As redes digitais representam hoje um fator determinante para a compreensão da expansão de novas formas de redes sociais e da ampliação de capital social na sociedade contemporânea. As diversas formas de comunidades virtuais, a estratégia $\mathrm{P} 2 \mathrm{P}$, as comunidades móveis, a explosão dos blogs e wikis, além de Orkut, Facebook, Whatsapp, Instagram são prova de que o ciberespaço constitui fator crucial no incremento do capital social e cultural disponível (COSTA, 2005).

Essa interconexão generalizada entre as pessoas na atualidade tem chamado a atenção de muitos teóricos sobre seus efeitos no quadro das relações individuais e igualmente na forma como os coletivos se comportam quando se constituem como redes de alta densidade (COSTA, 2005). Tal interconexão tem proporcionado, mudança de comportamento, desejo e ambição por coisas. Neste sentido, o sentimento de querer e ter são despertados por estímulos presentes neste meio e proporcionados intencionalmente por pessoas física ou jurídica no intuito de gerar comportamentos, que tragam resultados financeiros em algum momento. A busca pela a aparência, vulga estética das pessoas e coisas, tem sido um dos fatores que impulsionam os estímulos sofridos pelas pessoas de um grupo social.

E neste contexto, que as empresas utilizam o marketing digital, para promover produtos e despertar no grupo social a necessidade de tê-lo. Necessidade esta que se estende a esfera do compartilhamento e divulgação do consumo ou compra através do mesmo recurso. Tal ação configura como um ciclo. Percebe-se a plataforma digital como um recurso de faces, as quais podem ser exploradas por diferentes motivos, utilizando-se de diferentes forças e estratégias que em conjunto geram competitividade para os negócios.

\section{METODOLOGIA}

Esta pesquisa foi classificada como descritiva, quantitativa e estudo de caso. Pesquisas descritivas são aquelas que, segundo Gil (2010), buscam descrever atos e fenômenos. Estudam características de grupos, opiniões, atitudes e percepções de uma população. Assim, a presente pesquisa apresentou uma análise da eficiência dos recursos de marketing digital utilizados por uma empresa, prestadora de serviços automotivos em geral.

De acordo com Gil (2010), o estudo de caso é um estudo profundo e exaustivo de um ou 
de poucos objetos, permitindo o amplo e detalhado conhecimento daquilo que está sendo estudado. $\mathrm{O}$ estudo aconteceu exclusivamente na empresa em questão e seus resultados não podem ser extrapolados para outras organizações, de forma indiscriminada.

Em relação à abordagem do problema, esta pesquisa foi quantitativa, que tem por característica a análise de fenômenos a partir de métodos formais, caracterizados pela precisão e por controles numéricos e estatísticos. Empregam recursos quantitativos, cuja finalidade é a coleta sistemática de dados sobre populações ou programas (MARCONI; LAKATOS, 2008).

A coleta dos dados aconteceu por meio da aplicação de um questionário (APÊNDICE A), contendo questões fechadas, junto a uma amostra composta por 50 clientes da empresa, visando compreender se, segundo esses clientes, o marketing digital promove benefícios e vantagens, além de identificar quais são esses benefícios e essas vantagens.

Os dados obtidos foram tabulados e efetuados cálculo de porcentagem, identificando as mais representativas. Essas informações foram transformadas em tabelas e interpretadas a partir da fundamentação teórica, de forma a obter os resultados propostos para este trabalho.

\section{RESULTADOS DA PESQUISA}

\subsection{Perfil dos clientes}

Inicialmente foram apresentados os dados relativos ao perfil dos clientes da empresa estudada, a partir das variáveis: idade, sexo, escolaridade e destinatário do serviço contratado

Tabela 1 - Caracterização dos participantes da pesquisa

\begin{tabular}{|c|c|c|c|c|}
\hline \multicolumn{2}{|c|}{ VARIÁ VEL } & $\mathbf{n}$ & $\%$ & $\begin{array}{c}\% \\
\text { ACUMULADO }\end{array}$ \\
\hline \multirow{6}{*}{ IDADE } & 18 a 30 anos & 17 & $34 \%$ & $34 \%$ \\
\hline & 31 a 40 anos & 15 & $30 \%$ & $64 \%$ \\
\hline & 41 a 50 anos & 10 & $20 \%$ & $84 \%$ \\
\hline & 51 a 60 anos & 8 & $16 \%$ & $100 \%$ \\
\hline & Acima de 60 anos & O & $0 \%$ & $100 \%$ \\
\hline & Subtotal & 50 & $100 \%$ & \\
\hline \multirow{3}{*}{$S E X O$} & Masculino & 42 & $84 \%$ & $84 \%$ \\
\hline & Feminino & 8 & $16 \%$ & $100 \%$ \\
\hline & Subtotal & 50 & $100 \%$ & \\
\hline \multirow{4}{*}{ ESCOLARIDADE } & Ensino fundamental & 8 & $16 \%$ & $16 \%$ \\
\hline & Ensino médio & 27 & $54 \%$ & $70 \%$ \\
\hline & Ensino superior & 15 & $30 \%$ & $100 \%$ \\
\hline & Subtotal & 50 & $100 \%$ & \\
\hline \multirow{3}{*}{$\begin{array}{l}\text { DESTINATÁRIO } \\
\text { DOS SER VICGOS }\end{array}$} & Próprio entrevistado & 45 & $90 \%$ & $90 \%$ \\
\hline & Família ou amigo & 3 & $6 \%$ & $96 \%$ \\
\hline & $\begin{array}{l}\text { Empresa onde trabalha } \\
\text { Subtotal }\end{array}$ & $\begin{array}{c}2 \\
50\end{array}$ & $\begin{array}{c}4 \% \\
100 \%\end{array}$ & $100 \%$ \\
\hline
\end{tabular}

Fonte: Dados da pesquisa, 2018.

Pode-se observar pela tabela que existe predomínio de pessoas com até 40 anos (64\%), com escolaridade até o ensino médio (70\%) e que usam os serviços da empresa de limpeza para si mesmos (90\%). A grande maioria dos entrevistados é do sexo masculino (84\%), o que confirma que empresas de limpeza automotiva são ambientes predominantemente masculinos. 


\subsection{Hábitos de consumo}

Os hábitos de consumo em relação aos serviços de limpeza automotiva também foram investigados, a partir das variáveis: frequência de uso dos serviços, tipos de serviços e fator que levou o cliente até à empresa. Os dados obtidos estão na Tabela 02.
Em relação aos hábitos de consumo dos serviços de limpeza automotiva, os participantes apontaram que os usam uma vez por semana (70\%), sendo que esse serviço é, na grande maioria das vezes $(94 \%)$, referente à lavagem de automóveis.

Tabela 2 - Caracterização dos participantes da pesquisa

\begin{tabular}{|c|c|c|c|c|}
\hline \multicolumn{2}{|c|}{ VARIÁVEL } & $\mathbf{n}$ & $\%$ & $\begin{array}{c}\text { ACUMULAD } \\
0\end{array}$ \\
\hline \multirow{5}{*}{$\begin{array}{c}\text { FREQUENNCIA DE USO } \\
\text { DOS SERVIÇOS }\end{array}$} & 1 vez por semana & 35 & $70 \%$ & $70 \%$ \\
\hline & 1 vez por mês & 15 & $30 \%$ & $100 \%$ \\
\hline & 1 vez a cada 2 meses & 0 & $0 \%$ & $100 \%$ \\
\hline & 1 vez a cada 3 meses & 0 & $0 \%$ & $100 \%$ \\
\hline & Subtotal & 50 & $100 \%$ & $100 \%$ \\
\hline \multirow{3}{*}{$\begin{array}{c}\text { SERVIÇOS } \\
\text { UTILIZADOS }\end{array}$} & Lavagem de automóvel & 47 & $94 \%$ & $94 \%$ \\
\hline & Polimento/ enceramento & 3 & $6 \%$ & $100 \%$ \\
\hline & Subtotal & 50 & $100 \%$ & $200 \%$ \\
\hline \multirow{4}{*}{$\begin{array}{c}\text { FATOR QUE LEVOU O } \\
\text { CLIENTE ATÉ } \dot{A} \\
\text { EMPRESA }\end{array}$} & Facilidade de Acesso & 32 & $64 \%$ & $64 \%$ \\
\hline & Contato via canais digitais & 0 & $0 \%$ & $64 \%$ \\
\hline & Preço & 18 & $36 \%$ & $100 \%$ \\
\hline & Subtotal & 50 & $100 \%$ & $200 \%$ \\
\hline
\end{tabular}

Fonte: Dados da pesquisa, 2018.

Sobre os diversos fatores que levam o cliente até a empresa, dois foram destacados: a facilidade de acesso, citada por $64 \%$ dos entrevistados e o preço praticado pela empresa, apontado pelos demais 36\%. Apesar de ser uma resposta permitida, nenhum cliente citou que a possibilidade de contato com a empresa via canais digitais é fator importante que influencia o consumo dos serviços.

\subsection{Hábitos em relação à internet $\mathrm{e}$ ferramentas digitais}

Uma vez que a pesquisa trata de canais digitais de comunicação, foi necessário conhecer os hábitos dos clientes da empresa em relação ao uso da internet e das ferramentas digitais existentes. Foram realizadas perguntas que visaram identificar a frequência de acesso à internet, o uso de canais digitais e o acompanhamento aos canais digitais que existem na empresa em estudo. As respostas alcançadas estão ilustradas na Tabela 03:

A maior parcela dos entrevistados $(76 \%)$ disse que acessa à internet todos os dias. $\mathrm{O}$ recurso digital mais utilizado é o Whatsapp (74\%), seguido pelo Instagram (14\%).

Sobre a forma como conheceram a empresa, $48 \%$ disseram que foi por propaganda boca-a-boca e $38 \%$ por indicação de conhecidos. Ainda que houvesse a possibilidade de apontar que conheceu a empresa por intermédio dos canais digitais, nenhum cliente apontou essa alternativa. 
Tabela 3 - Hábitos em relação á internet e ferramentas digitais

\begin{tabular}{|c|c|c|c|c|}
\hline \multicolumn{2}{|c|}{ VARIÁ VEL } & \multirow{2}{*}{$\frac{\mathbf{n}}{38}$} & \multirow{2}{*}{$\frac{\%}{76 \%}$} & \multirow{2}{*}{$\begin{array}{c}\text { ACUMULADO } \\
76 \%\end{array}$} \\
\hline & Todos os dias & & & \\
\hline $\begin{array}{l}\text { FREQUENCIA DE ACESSO } \\
\text { A INTERNET }\end{array}$ & Não acessa & 12 & $24 \%$ & $100 \%$ \\
\hline & Subtotal & 50 & $100 \%$ & $100 \%$ \\
\hline \multirow{7}{*}{$\begin{array}{c}\text { RECURSOS QUE UTHLIZA } \\
\text { NODIA-A-DIA }\end{array}$} & Facebook & 5 & $10 \%$ & $10 \%$ \\
\hline & Instagram & 2 & $4 \%$ & $14 \%$ \\
\hline & Whatsapp & 30 & $60 \%$ & $74 \%$ \\
\hline & E-mail & 3 & $6 \%$ & $80 \%$ \\
\hline & SMS & 2 & $4 \%$ & $84 \%$ \\
\hline & Telefone celular & 8 & $16 \%$ & $100 \%$ \\
\hline & Subtotal & 50 & $100 \%$ & \\
\hline \multirow{5}{*}{$\begin{array}{c}\text { COMO CONHECEU A } \\
\text { EMPRESA }\end{array}$} & Boca-a-boca & 24 & $48 \%$ & $48 \%$ \\
\hline & Indicação & 19 & $38 \%$ & $86 \%$ \\
\hline & Passando em frente & 7 & $14 \%$ & $100 \%$ \\
\hline & Canais digitais & o & $0 \%$ & $100 \%$ \\
\hline & Subtotal & 50 & $100 \%$ & $100 \%$ \\
\hline \multirow{4}{*}{$\begin{array}{c}\text { ACOMPANHA PÁGINA NO } \\
\text { FACEBOOK }\end{array}$} & $\operatorname{Sim}$ & 2 & $4 \%$ & $4 \%$ \\
\hline & Não & 43 & $86 \%$ & $90 \%$ \\
\hline & Às vezes & 5 & $10 \%$ & $100 \%$ \\
\hline & Subtotal & 50 & $100 \%$ & $100 \%$ \\
\hline \multirow{4}{*}{$\begin{array}{c}\text { MANTEM CONTATO POR } \\
\text { WHATSAPP }\end{array}$} & $\operatorname{Sim}$ & 14 & $28 \%$ & $28 \%$ \\
\hline & Não & 12 & $24 \%$ & $52 \%$ \\
\hline & Às vezes & 24 & $48 \%$ & $100 \%$ \\
\hline & Subtotal & 50 & $100 \%$ & $100 \%$ \\
\hline \multirow{4}{*}{$\begin{array}{c}\text { DEIXARIA DE USAR } \\
\text { SERVICOS SE NAOO } \\
\text { HOUVESSE CANAAS } \\
\text { DIGITAIS }\end{array}$} & Sim & 2 & $4 \%$ & $4 \%$ \\
\hline & Não & 46 & $92 \%$ & $96 \%$ \\
\hline & Às vezes & 2 & $4 \%$ & $100 \%$ \\
\hline & Subtotal & 50 & $100 \%$ & $100 \%$ \\
\hline
\end{tabular}

Fonte: Dados da pesquisa, 2018.

Ainda em relação aos canais digitais utilizados pela empresa, $86 \%$ dos clientes entrevistados não acessam a página da empresa no Facebook, 28\% declararam que fazem contato regular com a empresa pelo aplicativo Whatsapp e $48 \%$ as vezes utilizam esta última ferramenta para contato com a empresa. Vale ressaltar que entre $076 \%$ dos participantes mantém contato sempre ou às vezes pelo Whatsapp, o que representa uma margem significativa para a empresa gerenciar e explorar mais ou uso deste recurso, enviando promoções, felicitações, novidades, etc.

Quando perguntados se deixariam de contratar os serviços da empresa caso ela parasse de usar os canais digitais, a grande maioria dos clientes $(96 \%)$ disse que não deixaria de usar os serviços de limpeza automotiva. Esse resultado é bastante interessante, uma vez que demonstra que a empresa não precisa dos canais digitais para atrair ou reter clientes. Também reflete o fato de que os clientes não consideram os canais digitais como ferramentas que representem diferencial competitivo para a empresa.

Esses dados confrontam diretamente tanto a percepção do proprietário, quanto da pesquisadora, que consideravam que os canais digitais contribuíram para o crescimento da empresa nos últimos anos. Esse fato que abre brechas para que a empresa explore tais ferramentas, tornando-as mais atrativas e fixando para seus clientes as mesmas como canais de comunicação para com a organização. Tais ferramentas possuem custo zero ou baixo custo, se comparadas a outras mídias, e geram grande envolvimento quando potencializadas, pois os clientes estão online e fazem o uso das redes, fato este comprovado, quando questionados se fazem o uso da internet e $76 \%$ confirmaram o uso. Observa-se que ainda não se sentem atraídos 
pela pouca comunicação existente entre estes meios para com eles.

\subsection{Avaliação dos canais digitais utilizados pela empresa}

O último bloco de questões buscou verificar a percepção dos clientes em relação aos canais digitais utilizados pela empresa. Em relação ao meio de comunicação utilizado para manter contato com a empresa, verificou-se que $73 \%$ dos participantes usam o Whatsapp e $27 \%$ o Telefone. A avaliação dos clientes em relação aos canais digitais oferecidos pela empresa está demonstrada na Tabela 04.

Tabela 4 - Avaliação dos clientes em relação ao atendimento prestado pelos canais digitais oferecidos pela empresa

\begin{tabular}{lccccccc}
\hline AVALIAÇÃO & ÓTIMO & $\begin{array}{c}\text { MUITO } \\
\text { BOM }\end{array}$ & BOM & RAZOÁVEL & RUIM & NÃO USO & TOTAL \\
\hline FACEBOOK & $0 \%$ & $0 \%$ & $4 \%$ & $10 \%$ & $0 \%$ & $86 \%$ & $100 \%$ \\
WHATSAPP & $4 \%$ & $22 \%$ & $12 \%$ & $12 \%$ & $0 \%$ & $50 \%$ & $100 \%$ \\
SMS & $0 \%$ & $0 \%$ & $0 \%$ & $0 \%$ & $0 \%$ & $100 \%$ & $100 \%$ \\
E-MAIL & $0 \%$ & $0 \%$ & $0 \%$ & $0 \%$ & $0 \%$ & $100 \%$ & $100 \%$ \\
\hline
\end{tabular}

Fonte: Dados da pesquisa, 2018.

Apenas dois recursos são utilizados pelos clientes, o Facebook e o Whatsapp. O atendimento via Facebook foi avaliado como bom por $4 \%$ dos participantes e avaliado como razoável por $10 \%$ dos entrevistados. Os demais $86 \%$ disseram que não usam esse canal de comunicação. Em relação ao Whatsapp, somente $4 \%$ disseram que o atendimento é ótimo; $22 \%$ que é muito bom. Metade dos entrevistados apontou que não usa essa ferramenta. Os demais canais (SMS e e-mail) não são usados pelos clientes entrevistados.

Também buscou-se investigar as vantagens e desvantagens que os canais digitais trazem para a empresa.

Tabela 5 - Vantagens e desvantagens dos canais digitais para a comunicação com o cliente

\begin{tabular}{clccc}
\hline & VARIÁVEL & $\mathbf{n}$ & $\boldsymbol{\%}$ & $\begin{array}{c}\text { \% } \\
\text { ACUMULADO }\end{array}$ \\
\hline \multirow{5}{*}{ VANTAGENS } & $\begin{array}{l}\text { Rapidez no atendimento } \\
\text { Melhoria na qualidade do } \\
\text { atendimento }\end{array}$ & 11 & $22 \%$ & $22 \%$ \\
& $\begin{array}{l}\text { Facilidade para entrar em } \\
\text { contato com a empresa } \\
\text { Nenhum }\end{array}$ & 11 & $22 \%$ & $44 \%$ \\
\hline \multirow{2}{*}{ DESVANTAGENS } & Sim, sem especificar qual & 5 & 27 & $46 \%$ \\
& Não & 45 & $90 \%$ & $100 \%$ \\
\hline & Subtotal & 50 & $100 \%$ & $10 \%$ \\
\hline
\end{tabular}

Fonte: Dados da pesquisa, 2018.

Em relação às vantagens, $22 \%$ acreditam que os canais digitais permitiram maior rapidez no atendimento, bem como melhoria na qualidade do atendimento. Para 54\% dos 
participantes não houve qualquer tipo de vantagem com a adoção desses recursos.

Já em relação à desvantagens, somente $10 \%$ disseram que existem desvantagens, mas não identificaram quais. Já para $90 \%$ não existem desvantagens na adoção de canais digitais pela empresa. Fato este que pode estar relacionado a presença da maioria dos clientes no ambiente virtual, através das redes sociais. Insight que oportuna a empresa potencializar de forma estruturada a comunicação e marketing através destes canais.

\section{CONCLUSÃO}

Os canais digitais não representam um diferencial competitivo para a organização, nem são a principal forma de comunicação com o cliente. Apesar de dispor desses recursos, a maioria dos clientes prefere manter contato com a empresa pelo telefone.

Os recursos digitais que se desenvolveram a partir das inovações tecnológicas vivenciadas pelo mundo nas últimas décadas estão influenciando a forma como as empresas fazem negócios.

Finalizada esta pesquisa, foi possível analisar a eficiência dos recursos de marketing digital utilizados pela empresa. Verificou-se que a empresa adota os canais de redes sociais como o Facebook para contato com seus clientes, bem como utiliza ferramentas virtuais de contato, como Whatsapp, SMS e e-mail.

Apesar de dispor desses recursos, a maioria dos clientes não mantém contato com a empresa por intermédio deles, preferindo o telefone. A principal forma como conheceram os serviços da empresa foi por indicação de terceiros. Procuram a empresa em virtude de sua localização e preço praticado.

A grande maioria dos participantes apontou que não conhecem a página da empresa no Facebook, não usam SMS, nem e-mail ou Whatsapp para contatar a organização. Também disse que esses canais não são diferenciais competitivos, uma vez que, se a empresa deixar de usá-los, isso não modificaria em nada a relação cliente/empresa. Tendo em vista o fato de que o relacionamento entre cliente e empresa é "estreito" e pontual, pode-se identificar uma clientela amiga e fiel.

Dessa forma, conclui-se que os canais digitais ainda não representam um diferencial competitivo para a organização, nem representam a principal forma de comunicação da empresa com o cliente. Contudo, tais informações podem ser utilizadas pela empresa, como forma de avaliação de sua performance nas redes sociais, instigando pesquisas futuras, para identificar o que chamaria a atenção de seus clientes, conferindo-lhe público e seguidores. Sabe-se que o segmento automotivo no Brasil movimenta boa parte da economia e apresenta inovações e novidades constantemente; as quais poderiam ser utilizadas a título de informação com o intuito de prospectar e gerar vendas.

\section{REFERÊNCIAS}

AMÂNCIO, M. F. C. Marketing digital e as novas ferramentas para atrair o consumidor do século XXI. 2009. 44f. Trabalho de Conclusão de Curso (Bacharelado em Administração) - Faculdade Cenecista de Capivari, 2009.

CATALANI, L.; KISCHINEVSKY, A.; RAMOS, E.; 
SIMÃO, H. E-commerce. 2 ed. São Paulo: FGV, 2006.

CINTRA, F. C. Marketing digital: a era da tecnologia on-line. Investigação, São Paulo, v. 10, n. 01, p. 6-12. 2010 .

COBRA, M. Administração de marketing no Brasil. 3 ed. Rio de Janeiro: Campus, 2009.

COSTA, L. M.; DIAS, M. M. S.; SANTOS, E. A.; ISHII, A. K. S. A evolução do marketing digital: uma estratégia de mercado. IN:: ENCONTRO NACIONAL DE ENGENHARIA DE PRODUCAO, 35., 2015. Artigo... Fortaleza/CE, out. 2015.

COSTA, R. Por um novo conceito de comunidade: redes sociais, comunidades pessoais, inteligência coletiva. Interface - Comunicação, Saúde, Educação, v. 09, n. 17, p. 235-248, mar./ago. 2005.

GABRIEL, M. Marketing na era digital. São Paulo: Novatec, 2010.

GIL, A. C. Como elaborar projetos de pesquisa. 5 ed. São Paulo: Atlas, 2010.

KOTLER, P. Marketing de A a Z: 80 conceitos que todo profissional precisa saber. 11 reimpressão. Rio de Janeiro: Campus, 2003.

; KELLER, K. L. Administração de marketing. 12 ed. São Paulo: Pearson Prentice Hall, 2006.

MCKENNA, R. Marketing de relacionamento. 2 ed. São Paulo: Publifolha, 2005.

MORAES, D. Comunicação virtual e cidadania: movimentos sociais e políticos na internet. Revista Brasileira de Ciências da Comunicação. v. 23, n. 02, jul./dez. 2000.

PADOVEZE, C. L. Sistemas de informações contábeis: fundamentos e análises. 4 ed. São Paulo: Atlas, 2004.

PASA, E. C. O uso de documentos eletrônicos na contabilidade. Revista Contabilidade e Finanças da Universidade de São Paulo, São Paulo, v. 14, n. 25, p. 72-783, jan./abr. 2001.

PINHO, J. B. Publicidade e vendas na internet. São Paulo: Summus, 2000.

PRIMO, A. F. T. A emergência das comunidades virtuais. 2007.2 Disponível em: <http://www.ufrgs.br/limc/PDFs/comunidades_virtuai s.pdf $>$. Acesso em: 25 maio. 2017.

REQUETO, R. C. Comunidades virtuais em redes sociais na internet: uma proposta de estudo. 2006.
Disponível em:

< http://www.raquelrecuero.com/seminario2005.pdf $>$. Acesso em: 07 maio. 2017.

SILVA, G. M. B.; DAOLIO, R. P. G. A importância da internet como ferramenta estratégica para o negócio da empresa. Revista Gestão em Foco, n. 09, p. 132137, 2017.

SILVA, J. C. T. Tecnologia: Conceitos e dimensões. In: Encontro Nacional de Engenharia de Produção, 22., 2002, Curitiba. Artigo... Curitiba: Encontro Nacional de Engenharia de Produção, 2002.

SILVA, S. F. Marketing de serviços. Maceió: Edufal, 2005.

VERASZTO, E. V.; SILVA, D.; MIRANDA, N. A.; SIMON, F. O. Tecnologia: buscando uma definição para o conceito. Revista Prisma, v. 7, 2008.

WARREN, I. S. Das mobilizações às redes de movimentos sociais. Sociedade e Estado, Brasília, v. 21, n. 01, p. 109-130, jan./abr. 2006.

\section{João Batista Ferreira}

Mestre em Gestão Organizacional (UFG). Docente e coordenador do curso de administração pela Faculdade Cidade de Coromandel.

\begin{tabular}{l}
\hline Maicon Figueiredo Ferreira \\
Especialização em Tecnologias para aplicações WEB \\
pela UNOPAR. Docente e coordenador do curso de \\
analise e desenvolvimento de sistemas pela \\
Faculdade Cidade de Coromandel. \\
\hline
\end{tabular}

